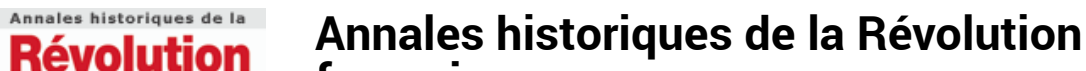

française française

344 | avril-juin 2006

La prise de parole publique des femmes

\section{Correspondance (1770-1793)}

\section{Michel Biard}

\section{(2) OpenEdition}

\section{Journals}

Édition électronique

URL : https://journals.openedition.org/ahrf/6663

DOI : 10.4000/ahrf.6663

ISSN : 1952-403X

Éditeur :

Armand Colin, Société des études robespierristes

Édition imprimée

Date de publication : 1 juin 2006

Pagination : 456-457

ISSN : 0003-4436

\section{Référence électronique}

Michel Biard, «Correspondance (1770-1793) ». Annales historiques de la Révolution française [En ligne], 344 | avril-juin 2006, mis en ligne le 02 juillet 2008, consulté le 24 avril 2022. URL : http:// journals.openedition.org/ahrf/6663 ; DOI : https://doi.org/10.4000/ahrf.6663

Ce document a été généré automatiquement le 24 avril 2022.

Tous droits réservés 


\title{
Correspondance (1770-1793)
}

\author{
Michel Biard
}

\section{RÉFÉRENCE}

MARIE-ANTOINETTE, Correspondance (1770-1793), édition établie et présentée par Évelyne Lever, Paris, Tallandier, 2005, 912 p., ISBN 2-84734-197-8, $35 €$

1 De toute évidence, la France connaît depuis quelques années un énième retour sur le devant de la scène historiographique des époux royaux guillotinés en 1793, à un point tel que la revue L'Histoire est allée jusqu'à titrer dans son numéro de novembre 2005 : «Louis XVI. Faut-il le réhabiliter? ». Il aurait été tentant de croire que des historiens n'aient pas à se poser ce genre de question, par essence étrange, et que nous n'avions pas besoin d'un nouveau sondage afin de savoir si les Français d'aujourd'hui voteraient ou non en faveur de la mort de « Louis Capet ». Force est toutefois de déchanter et il est probable hélas que la prochaine vision de Marie-Antoinette sur le grand écran, filtrée par un scénario romancé et par les charmes inhérents au "système » hollywoodien, quoique servie par une réalisatrice de talent (S. Coppola), n'aura guère à envier à ce genre de phénomène. Fort heureusement, la présente édition de la correspondance de la reine ne sombre pas dans cette Toinettomania qui semble devoir nous menacer et Évelyne Lever nous livre ici un gros et utile volume.

2 Toute la correspondance, active et passive, de Marie-Antoinette s'y trouve rassemblée, $\mathrm{du}$ « règlement à lire tous les mois » remis par Marie-Thérèse à sa fille le 21 avril 1770, jour de son départ pour la France, à l'ultime lettre écrite de prison le 16 octobre 1793, au matin même de son exécution. D'autres lettres ont été jointes à l'ensemble, afin d'éclairer celles envoyées et reçues par Marie-Antoinette, notamment de nombreuses missives du comte de Mercy-Argenteau. Le tout a été rangé par ordre chronologique et fait ainsi apparaître de grands blocs: une décennie de relations épistolaires avec sa mère (qui a annoncé par avance l'assiduité qui devait être la sienne tout au long des années 1770 : «Tous les commencements de mois, j'expédierai d'ici à Paris un courrier [...]») nous vaut tout d'abord quelque 350 pages; suivent alors les correspondances 
avec les deux frères de la reine devenus empereurs, d'abord Joseph II, puis Léopold II ; près de 300 pages sont ensuite réservées à la passionnante correspondance des années 1791 et 1792, avec notamment les courriers échangés avec Barnave, mais aussi avec Fersen; avant que, pour d'évidentes raisons, les écrits de 1793 soient réduits à la portion congrue. Les historiens connaissaient naturellement ces lettres, mais il fallait pour les consulter recourir à des publications diverses et Évelyne Lever simplifie leur tâche en les rassemblant, avec une table chronologique, une table des correspondants et un index des noms de personnes. Le tout est accompagné d'une introduction d'une vingtaine de pages, qui éclaire utilement le contenu de l'ouvrage, même si deux erreurs de belle taille auraient pu aisément être évitées : l'Assemblée constituante n'a pas pu, en 1791, chercher à écarter «[...] l'instauration de la république souhaitée par Robespierre et ses amis [...]», ou alors ce serait une découverte majeure de savoir que Robespierre était alors républicain (p. 23); et un commentaire à propos de la réunion de l'Assemblée législative laissera pour le moins rêveur quiconque connaît, d'une part, les travaux sur les Législateurs, d'autre part, ceux réalisés sur les pouvoirs exécutif et législatif pendant la Révolution française ( Si les députés nouvellement élus manquent d'expérience, ils ne se considèrent pas moins comme les maitres du pouvoir exécutif et du pouvoir législatif », p. 29).

3 Pour le reste, il est naturellement impossible de citer ici toutes les lettres intéressantes, car elles sont légion comme chacun s'en doute. Je me contenterai donc de signaler tout l'intérêt des années 1770, dans la mesure où les jolis échanges d'une mère avec sa fille y voisinent avec les grandes affaires du temps, avec des jugements sur tel ou tel personnage (Madame du Barry perçue par la jeune Dauphine comme « [...] la plus sotte et impertinente créature qui soit imaginable »), avec de précieuses indications sur la vie culturelle et l'« opinion publique ", avec des précisions sur ses lectures (l'Histoire d'Angleterre de Hume lui « [...] paraît fort intéressante, quoiqu'il faille se souvenir que c'est un protestant qui l'a composée »), ou encore bien sûr avec le regard porté sur son royal époux qui confirme à bien des égards les ragots quant à l'appétit sexuel de celui-ci ( Il est bien constitué, il m'aime et a bonne volonté, mais il est d'une nonchalance et paresse qui ne le quitte jamais que pour la chasse »). Quant aux correspondances des années 1791 et 1792, lorsque la reine doit s'habituer au secret et aux encres qu'elle n'arrive parfois pas à "faire sortir » à l'aide des produits adéquats, lorsqu'elle avoue "[...] je suis fatiguée à force d'écritures, jamais je n'ai fait un tel métier [...]», lorsque ses lettres impliquent au plus haut point la politique de Louis XVI et révèlent de manière flagrante le double jeu mené, lorsqu'elles prêchent la guerre (pour «[...] qu'enfin on se venge de tous les outrages qu'on reçoit de ce pays-ci ») et dévoilent les plans militaires... elles sont d'autant plus passionnantes à lire en détail qu'elles jettent une lumière crue sur les diverses manœuvres tentées par le couple royal et son entourage, ainsi que par tous ceux qui se sont prêtés au jeu des échanges politiques secrets pour établir ou rétablir leur influence (Barnave et ses amis du Triumvirat, pour ne citer qu'eux).

Ce gros volume intéressera sans doute un certain nombre de nostalgiques et les amateurs du genre biographique, mais son intérêt en tant que recueil de sources, pratique à manier grâce à ses tables et index, en fait surtout un ouvrage essentiel pour tous ceux qui étudient la période révolutionnaire. 